\title{
ВЛИЯНИЕ КОНТРОЛЯ ГЛИКЕМИИ НА ТЕЧЕНИЕ САХАРНОГО ДИАБЕТА
}

\author{
Кошукова Г.Н., Репинская И.Н., Доля Е.М.
}

Медицинская академия им. С.И. Георгиевского, ФГАОУ ВО «КФУ им. В.И. Вернадского», Симферополь

\begin{abstract}
АКТУАЛЬНОСТЬ: комплексная терапия сахарного диабета (СД), наряду с медикаментозной терапией, предусматривает модификацию образа жизни, диетотерапию, контроль гликемии, регулярную физическую активность, выявление осложнений и лечение сопутствующих заболеваний. Только 1 из 5 пациентов достигает рекомендованных целей контроля гликемии, что обуславливает особое место контроля гликемии как в терапевтическом, так и в прогностическом плане.
\end{abstract}

ЦЕЛЬ: изучить влияние контроля гликемии на течение сахарного диабета.

МАТЕРИАЛЫ И МЕТОДЫ: проведено ретроспективныЙ анализ медицинской документации 362 больных СД 2 типа (163 мужчины и 199 женщин, средний возраст - 56,1 23,9 лет) сдлительностью заболевания более 1 года, на базе ГБУЗ РК «РКБ им. Н.А. Семашко». Пациенты были разделены на группы в зависимости от применяемых методов контроля гликемии: пациенты 1-й группы $(\mathrm{n}=61)$ проводили эпизодический контроль гликемии при посещении медицинских учреждений, не пользовались индивидуальными приборами контроля; пациенты 2-й группы $(\mathrm{n}=217)$ регулярно контролировали уровни гликемии при помощи глюкометров в домашних условиях и пациенты 3-й группы $(\mathrm{n}=84)$ наряду с проведением контроля гликемии в домашних условиях 1 раз в месяц проводили анализ гликемии по показателям индивидуальных глюкометров с помощью аппарата Глюкопринт (производство ООО НПП «Политех-Автоматика») с их визуализацией.

РЕЗУЛЬТАТЫ И ОБСУЖДЕНИЕ: анализ индекса массы тела (ИМТ) не Показал статистически достоверных различий среди пациентов трех групп. Однако у больных 1-й группы отмечался минимальный процент достижения целевых уровней гликемии - 24,6\%. Вместе с тем у 57,4\% больных регистрировалась артериальная гипертензия (АГ), гиперхолестеринемия (ГХ) - у 50,8\% больных, микроальбуминурия

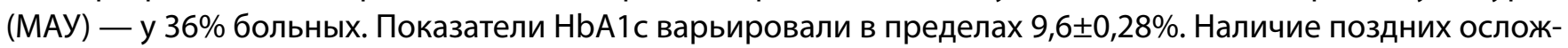
нений СД выявлено у $41 \%$ больных. Нормогликемия среди пациентов 2-й группы фиксировалась в $48,4 \%$

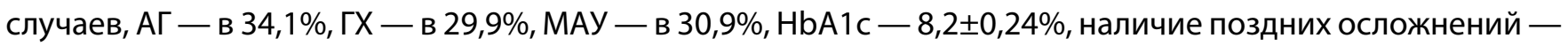
34,6\%. Пациенты 3-й группы продемонстрировали наилучшие показатели: нормогликемия - 64,3\%, АГ-

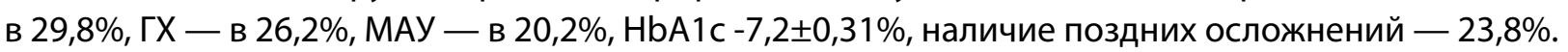

Полученные результаты продемонстрировали достоверные $(p<0,05)$ различия показателей при использовании разных методов контроля гликемии. Выявлена прямая корреляционная связь уровня гликемии и частотой развития коморбидных состояний и поздних осложнений СД. Использование визуализации позволяет достигать целевых показателей у большинства пациентов, снизить показатели НbA1c на 0,74\% по сравнению с исходными данными.

ВЫВОдЫ: использование современных технологий (аппарат Глюкопринт) в повседневной практике позволяет проводить более качественный контроль и терапию СД. Визуализация уровня гликемии помогает быстро провести анализ показателей в динамике, акцентировать внимание пациента на достигнутых результатах, повышает уровень приверженности пациента к проводимой терапии, что в перспективе уменьшит риск развития осложнений СД.

КЛЮЧЕВЫЕ СЛОВА: сахарный диабет; гликемия; контроль; осложнения. 